\section{International Scientific Journal Theoretical \& Applied Science}

p-ISSN: 2308-4944 (print) e-ISSN: 2409-0085 (online)

Year: 2018 Issue: 02 Volume: 58

Published: $28.02 .2018 \quad$ http://T-Science.org

SECTION 4. Computer science, computer engineering and automation.
Andrei Mastislavovich Korneev

Doctor of Technical Sciences, Professor, director of the institute of Lipetsk State Technical University, Russia, Lipetsk

Andrei Vladimirovich Sukhanov postgraduate student, assistant of Lipetsk State Technical University, Russia, Lipetsk

Ilya Andreevich Shipulin postgraduate student, assistant of Lipetsk State Technical University, Russia, Lipetsk

\title{
SYSTEM METHODOLOGY IN THE ANNEX TO THE PREDICTION OF THE PROPERTIES OF CAST IRON ALLOYS
}

\begin{abstract}
The article substantiates the presentation of cast iron alloys as a material with a composite structure, and formulates the principles of a systematic approach to predicting the properties of cast iron alloys. The processes of controlling the structure formation of materials with a complex composite structure, which are studied taking into account the information circulating in it, are considered in the system. Significant components of the structure of the control system, which are characteristic for most types of structures, that allow synthesizing a material with certain properties, are indicated. The characteristic features of the systems contained in the definitions are listed, as well as the properties that characterize the integrity of the system. The system-forming factors that characterize the organization of developing systems are described in detail. Formal requirements are formulated for decision-making systems for managing the processes of optimizing the structure and properties of cast iron alloys. Practical examples are given, with a substantiation of the principles of completeness of the internal structure of systems characterized by functional integrity.

Key words: decision-making system, cast-iron alloy, chemical composition, composite structure, cast iron expansion coefficient, specific heat of cast iron.

Language: English

Citation: Korneev AM, Sukhanov AV, Shipulin IA (2018) SYSTEM METHODOLOGY IN THE ANNEX TO THE PREDICTION OF THE PROPERTIES OF CAST IRON ALLOYS. ISJ Theoretical \& Applied Science, 02 (58): 181-186.
\end{abstract}

Soi: http://s-0-i.org/1.1/TAS-02-58-38 Doi: crossef https://dx.doi.org/10.15863/TAS.2018.02.58.38

\section{Introduction}

Among the new research methodologies formed so far, four main and complementary approaches can be identified: synergistic, homeostatic, systemic and informational [1].

A systematic approach to the scientific knowledge of the properties and nature of the structure of materials with a composite structure gave a powerful impetus to the development in science of new directions characterized by the application of known methods of system theory to the development of control algorithms for the formation of rational chemical compositions for structures in various industries. An important methodological and scientific value of the system approach is that it allows researchers to identify and formulate the principles of systemic nature, manifested in the process of formation of chemical compounds. In modern system methodologies used in the application to the development and structuring of materials with a composite structure, an approach is increasingly being used that is a set of methods and tools that allow one to investigate both the properties, structure and functions of individual elements and composites of an object, interaction, that is, to study the intrastructural processes as a whole, presenting them as systems with all the complex interelement links by the interaction of elements on the system itself and on the surrounding first medium [1, 2, 3, 4].

\section{Materials and Methods}

When studying any complex system, object or phenomenon, the system approach is based on their holistic vision, with the main feature of the system approach being the prevailing role of the whole over the individual and complex over simple $[5,6]$. Note that although the main properties and results of the system's activity depend to a large extent on the composition and properties of the elements entering into it, but in principle cannot be studied at the level of exclusively the characteristics of these elements $[4,6,7]$. This observation was taken into account by the researchers using the system approach in the 
application to the design and calculation of materials having a composite structure $[2,3,4,6]$, as well as for materials whose composite structure is provided by the arrangement of phases cast irons with special eutectics) [8, 9]. For technical objects with a complex internal structure, it is the holistic, synthetic description that makes it possible to link their various elements, previously considered separately, together $[10,11]$.

One can also not ignore the processes of controlling the structure formation of materials with a complex composite structure occurring in the system [8]; these processes require a separate study of the system with respect to the information circulating in it.

Since in the modern understanding the system is a collection of interconnected elements united by functional integrity and unity of purpose (here the property of the whole system is not reduced to the sum of the properties of its individual elements), its properties as a whole are set not only by the properties of the individual elements but also properties of its structure. For most types of systems that allow to structure a material with certain properties, among the significant components of the structure of the control system indicate:

- the spatial arrangement of all elements of the system;

- stable links between the elements of the system;

- the internal arrangement of the system;

- laws that determine the mutual influence, the interaction of elements within the system.

Since any system is formed as a result of the interaction of its constituent elements, which gives the system new properties that are not characteristic of individual elements, the number of properties of the system, as a rule, exceeds the sum of the properties of the individual elements; the difference is a new system properties. Completeness of the internal structure of the system is characterized by functional integrity, and several interrelated elements of the structure form a system only if the relations between the elements of the system generate a new system quality different from the previous ones, called integrative. Thus, in the wear-resistant highalloyed white cast iron used for the production of critical parts, there is a large amount of ferritic component concentrating around the carbides [12]. The influence of such structural impregnations reduces the wear resistance due to the weakening of the bond between ferrites and chromium carbides. In this case, the system (material having a composite internal structure) is formed from elements (ferrites, chromium carbide, austenite, cementite, graphite, perlite) as a result of the appearance of a new property-adhesion.

Strict, correct and unambiguous definition of the system for today does not exist. However, there are many different, albeit close to each other, definitions of the system and its structure. More often define a system as a set of elements, united through a series of relationships that generate a systemic, or integrative, quality by which the given set is distinguished from the environment, and to which each of its components is attached.

In some cases, the concept of the system is used incorrectly, for example, in cases where the integrative quality does not take place (the unification of parts in the system does not lead to the appearance of a new property different from those that the individual parts had before unification).

An example of such a system is iron-carbon, whose structure consists of various components (austenite, cementite, graphite, perlite) with certain properties (specific heat, coefficient of casting expansion, thermal conductivity, etc.). It is obvious that the composition and structure of pig iron depend on the constituent components.

The greatest influence on the coefficient of foundry expansion is provided by carbon, which is in a bound state. At $1 \%$ of carbon, as a rule, there is about 5 times less graphite than cementite. Therefore antigravniziruyuschie ( $\mathrm{Mn}, \mathrm{V}, \mathrm{W}, \mathrm{Cr}, \mathrm{Mo}$, etc.) are reduced, and the graphitizing elements $(\mathrm{Al}, \mathrm{Si}, \mathrm{Ni}$, $\mathrm{Ti}, \mathrm{Cu}$, etc.) increase the coefficient of linear expansion.

The largest value of the coefficient of foundry expansion is austenitic cast iron with nickel additive, as well as ferritic aluminum cast irons. Therefore, at sufficiently high contents of $\mathrm{Mn}, \mathrm{Cu}, \mathrm{Ni}$, the value of the coefficient of specific expansion sharply increases. The shape and structure of graphite also has a significant effect on the coefficient of linear expansion, but only at low temperatures; the coefficient of foundry expansion with lamellar graphite with spherical graphite is somewhat lower than that of high-strength cast iron [13].

The specific heat capacity of cast iron increases with increasing temperature and is characterized by a stepwise increase in phase transformations, after which the specific heat of cast iron decreases, but with a further increase in temperature again increases. On the contrary, graphitization contributes to lowering the specific heat of cast iron [13].

The thermal conductivity of cast iron is also strongly dependent on its structure, the presence of minute impurities and its dispersion, which characterizes this factor as a structurally sensitive property. The shape of the graphite, its distribution and isolation also have a significant effect on the thermal conductivity. For example, gray cast iron has a higher thermal conductivity than high-strength cast iron. It is known that high-alloyed cast iron is characterized, as a rule, by a lower thermal conductivity than conventional cast iron $[13,14]$.

Taking into account the above examples, it should be noted that it would be erroneous, as a 


\begin{tabular}{|c|c|c|c|c|c|c|}
\hline Impact Factor: & $\begin{array}{l}\text { ISRA (India) } \\
\text { ISI (Dubai, UAE } \\
\text { GIF (Australia) } \\
\text { JIF }\end{array}$ & $\begin{array}{l}=1.344 \\
=0.829 \\
=0.564 \\
=1.500\end{array}$ & $\begin{array}{l}\text { SIS (USA) } \\
\text { PИНЦ (Russia) } \\
\text { ESJI (KZ) } \\
\text { SJIF (Morocco) }\end{array}$ & $\begin{array}{l}=0.912 \\
=0.207 \\
=4.102 \\
=\mathbf{2 . 0 3 1}\end{array}$ & $\begin{array}{l}\text { ICV (Poland) } \\
\text { PIF (India) } \\
\text { IBI (India) }\end{array}$ & $\begin{array}{l}=6.630 \\
=1.940 \\
=4.260\end{array}$ \\
\hline
\end{tabular}

system, to consider the formal union of individual components in (the properties of the system here are identical to the sum of the properties of the given layers) $[2,3]$.

The most significant properties and features of the system are indicated in [5]. The system here refers to the totality of elements that are in a definite connection with each other, and form the integrity and unity. The most widespread and recognized this definition was obtained from domestic researchers $[2,3]$.
Some types of objects that are called systems are not covered by the currently available system definitions, but this does not prevent distinguishing systems from other objects [2, 3, 5]. The most characteristic features of systems contained in the definitions are the following: the presence of a structure; integrity of the set of system elements; stable links between the elements of the system; the organization of developing systems (Figure 1).

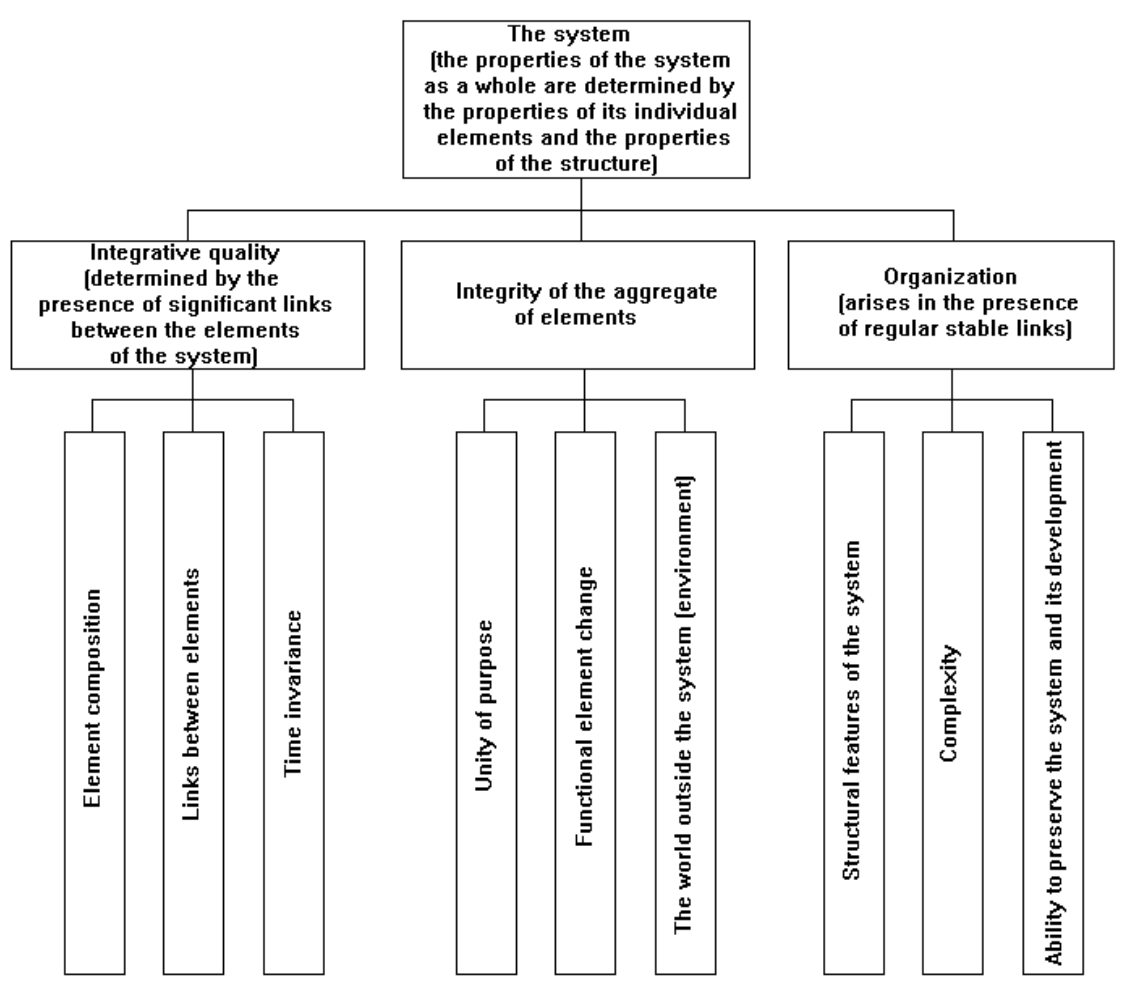

Figure 1 - Characteristic features of the system

The structure is a form of representation of the object in the form of separate parts, as well as a set of relationships that are only possible between elements within the system itself. The system is also that which remains unchanged when the state of the system changes and when the system performs certain operations [15]. It is always necessary to indicate which part of the system and what its properties and attributes are structural and which are not, since the structure is part of the system. In practice, many real systems do not lend themselves to a simple description because of the high complexity of their structures. In this connection, the structural elements of the system were understood as its smallest part, the behavior of which is still subject to the laws of the system. Their own structural elements can be contained within the elements of the structure themselves, which generates the hierarchy principle in the construction of connections between systems, which presupposes subordination of the subsystem to the system and the system of the supersystem. Such systems are called structured systems [2, 3].

The integrity of the system is characterized by the internal unity of the elements entering into it and the fundamental irreducibility of its properties to the sum of the properties of these elements. Relationships that give integrity to a multitude of elements are called system-forming. The features of the system that distinguish it as a separate whole are important characteristics that are called integrative. These features are not inherent in the individual elements of the system, but are inherent in the system as a whole. The connection of individual elements to the system occurs through the formation of a coordinated interaction into something new. At the same time, the new must have an integrative quality, which the elements did not have before the merger. 
For example, in the case of cast-iron alloys, control of the process of modification, microalloying, alloying and heat treatment. System-forming relations express integral integrative properties of the system and are also internal for the given system, and hence determine its specificity. For example, in the absence of adhesion interactions, any material with a composite structure is converted into a mixture of disconnected components.

From a conventional conglomerate, the system is distinguished by the presence of integrative properties, and the presence of stable links between the elements of the system, as well as the information exchange between them, the environment and the system, isolate the system from the surrounding environment in the form of an integrated formation. It is known that in most materials with a composite structure, the bond between individual components of the structure is due to chemical bonding forces, adhesion or through autohesion.

The organization of developing systems is characterized by the following system-forming factors:

- the number of system elements;

- the number of significant links that the system elements may have;

- the number of element properties that are significant for the system;

- the number of quantums of space and time in which the elements of the system can be located.

There is a close relationship between the concepts of "system" and "organization." In the case of cast iron alloys, the properties are largely determined by the presence and percentage of alloys $[8,9,12]$.

Often a negative result in the form of a degeneration of the system results from its extra "reorganization" with a decrease in the entropy of the system to practically zero. An excessive increase in entropy is also unacceptable. For example, highstrength cast iron with increased strength characteristics is a reorganized system with low entropy, whereas ordinary glass is a system with low organization.
We note that often the concept of the system erroneously spreads practically to all objects that are of a complex nature, including irrational types of interrelations and interactions. Sometimes by the system we mean the aggregate of integral objects that do not have unified sources of control, or contain conflicting and contradictory interactions.

Based on a holistic view of phenomena, processes and objects, system thinking and a systematic approach to the synthesis of cast iron alloys with a composite structure allow the use of both deductive (systemic problems are determined, after which the solution is sought) and inductive (in the beginning a new idea is sought, after which it is used to solve the emerging systemic problems) of thinking methods.

Summarizing the foregoing, we note that the systematic approach to the development of cast iron alloys having a complex composite structure can be considered very relevant and timely.

In the process of studying a complex structured object from different points of view and using various conceptual or formalized models, as a rule, the elements of the system, subsystems and supersystems are preliminarily distinguished. In the case where the object of structural investigation is a material with a composite structure, the subject is the chemical composition, structure, phase inclusions, bonds, etc. In functional research, the subject is rheological and kinetic processes (material destruction, sorption of aggressive environments), resistance to operating conditions, eco-nomicity (with unchanged structure depends on the properties of the elements of a given structure).

Experience established that many objects, phenomena and processes in the structure of materials inherent typical properties of the system (dependence or relationship), - with a high frequency observed patterns $[2,3]$. The identification and study of such regularities greatly facilitates the transfer from one area to another of knowledge about the basic processes taking place in complex structured systems. It also helps to determine the direction, limits of development and improvement of systems. 


\begin{tabular}{l|lr|ll|ll} 
& ISRA (India) & $=\mathbf{1 . 3 4 4}$ & SIS (USA) & $=\mathbf{0 . 9 1 2}$ & ICV (Poland) & $=\mathbf{6 . 6 3 0}$ \\
Impact Factor: & ISI (Dubai, UAE) $=\mathbf{0 . 8 2 9}$ & PUHЦ (Russia) $=\mathbf{0 . 2 0 7}$ & PIF (India) & $=\mathbf{1 . 9 4 0}$ \\
& GIF (Australia) & $\mathbf{0 . 5 6 4}$ & ESJI (KZ) & $=\mathbf{4 . 1 0 2}$ & IBI (India) & $\mathbf{4 . 2 6 0}$ \\
& JIIF & $=1.500$ & SJIF (Morocco) & $=\mathbf{2 . 0 3 1}$ & & \\
\hline
\end{tabular}

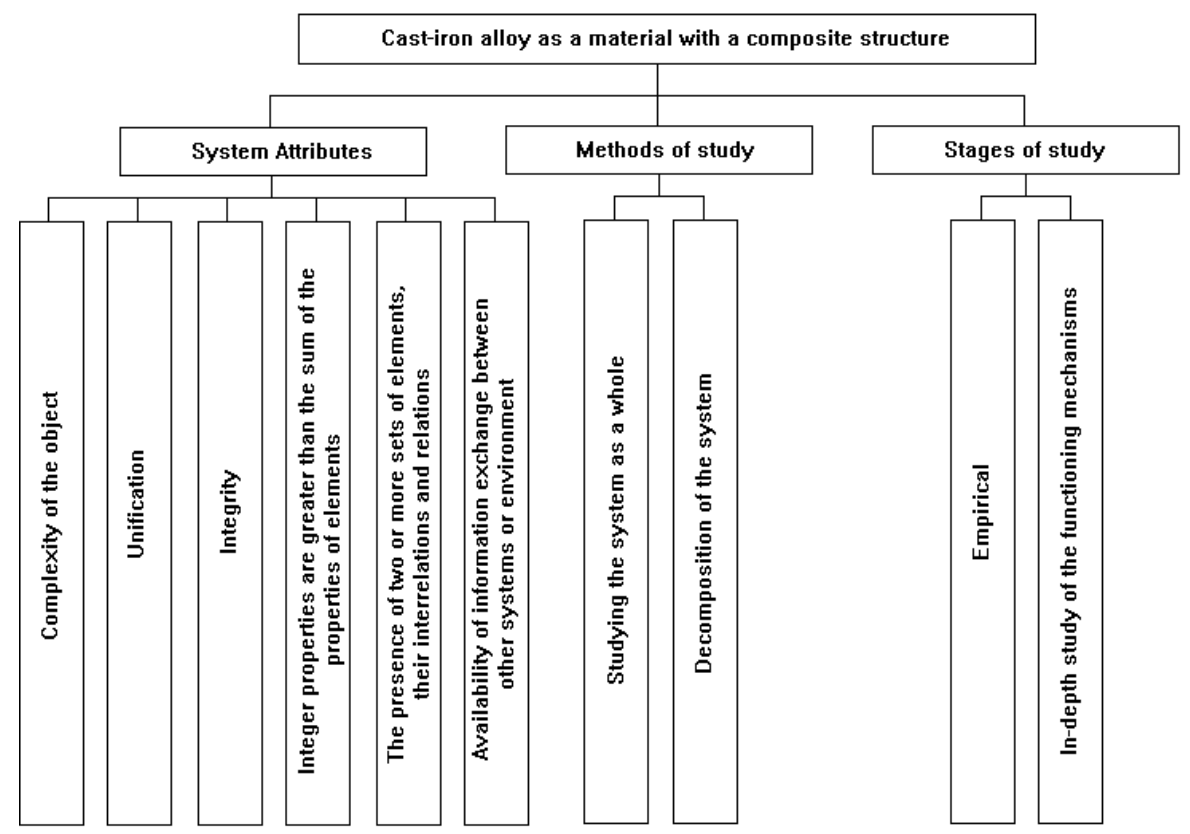

Figure 2 - Material with a composite structure as a system

\section{Conclusion}

It is known that the system's potential depends on the degree of organization of the system or the nature of the interaction of its structure [16]. Such entropy uniformity makes it possible to determine the dependence of the system potential on structural elements for systems with different degrees of organization, in order to further select recommendations for decision making and system management.

Note that at the present time among the various systems theories there is no universal, suitable for any practical problems. This also applies to the general theory of systems with high abstraction, which allows in the definition of the system more than twenty attributes or attributes.
When considering cast-iron alloys that have a composite structure, as systems, the following main attributes (attributes) can be distinguished: integrability; integrity; presence of several sets of composite elements, relations between them and relations; the exchange of information between the environment or other systems (Figure 2).

In the study of such systems, under the rule, in most cases, one often understands the often observed property (dependence or connection) that is inherent in several objects, phenomena and processes, established as a result of the experiment (the process of forming physical characteristics, the dependence of the operator's control on the information parameters) [17].

\section{References:}

1. Danilov A.M. (1995) Systems and models [Text]: Textbook / A.M. Danilov. - Penza: PGAAS, 1995, - $200 \mathrm{p}$.

2. Garkina, I.A. (2014) Experience in optimizing a multipurpose system / IA Garkina, TN. Volkova // Modern scientific research and innovations. - 2014. - №10. - p.1.

3. Garkina IA, Danilov AM, Smirnov VA (2008) Flocculation in disperse systems of control system and information technology. - 2008. No. 2.3 (32) .- p. 344-346.

4. Prangishvili I.V. (2005) Improving the management efficiency of complex organizational and socio-economic systems / I.V. Prangishvili // Problems of Management. 2005. - №5. - p.28-32.

5. Blauberg I.V. (1973) Formation and essence of the system approach: monograph / I.V. 


\begin{tabular}{l|lr|ll|ll} 
& ISRA (India) & $=\mathbf{1 . 3 4 4}$ & SIS (USA) & $=\mathbf{0 . 9 1 2}$ & ICV (Poland) & $=\mathbf{6 . 6 3 0}$ \\
Impact Factor: & ISI (Dubai, UAE) $=\mathbf{0 . 8 2 9}$ & PUHЦ (Russia) $=\mathbf{0 . 2 0 7}$ & PIF (India) & $=\mathbf{1 . 9 4 0}$ \\
& GIF (Australia) & $=\mathbf{0 . 5 6 4}$ & ESJI (KZ) & $=4.102$ & IBI (India) & $=\mathbf{4 . 2 6 0}$ \\
& JIF & $=\mathbf{1 . 5 0 0}$ & SJIF (Morocco) & $=\mathbf{2 . 0 3 1}$ & & \\
\hline
\end{tabular}

Blauberg, E.G. Yudin. - Moscow: Nauka, 1973. - $270 \mathrm{p}$.

6. Prangishvili I.V. (2000) A systematic approach and system-wide regularities: a scientific publication / I.V. Prangishvili - M .: SYNTHEG, - 2000. - $528 \mathrm{p}$

7. Sadovsky, V.N. (1969) Investigations on the general theory of systems. Sadovsky, E.G. Yudin. - M .: Progress. - 1969. - 520 p.

8. Pechenkina L.S. (2017) Optimization of the composition of self-hardening cast irons / L.S. Pechenkina // Bulletin of the Voronezh State Technical University. - 2017. - № 6.

9. Pechenkina L.S. (2000) Development of wearresistant self-hardening alloys for thin-walled precision parts: Dis. Cand. tech. Sciences: 05.16.01: It is protected on the 20.06.200: ut. 12.12.2000 / L.S. Pechenkina - Kursk, 2000. $193 \mathrm{p}$.

10. Buslenko N.P. (1968) Modeling of complex systems: monograph / N.P. Buslenko. Moscow: Nauka, - 1968. - 355 p.

11. Kukhtenko A.R. (1968) The main tasks of managing complex systems / A.R. Kukhtenko // Complex control systems: Sat. sci. works. Kiev. - 1968. - Issue. 1. - p.27-39.
12. Radchenko KS (2011) Optimization of the chemical composition of wear-resistant highalloyed white cast irons / K.C. Radchenko, G.E. Fedorov, M.M. Yamshinsky // Metal and casting of Ukraine. - 2011. - №1. - p.20-23.

13. Tarasutin TG (1963) Method for determining the thermophysical coefficients of a nonmetallic casting mold. In the book. Thermophysics in Foundry, Ed. A.I. Veinik. Minsk, publishing house of the Academy of Sciences of the BSSR. 1963. -p. 74-77.

14. Tikhomirov M.D. (1990) Heat transfer across the border "casting-form" with solidification of aluminum alloys, - M.: Foundry production.1990, No. 6.-p. 18-19.

15. Nikolayev V.I. (1985) Systematics: methods and applications: monograph / V.I. Nikolaev, V.M. Brooke. - L .: Mechanical Engineering, 1985. - $199 \mathrm{p}$.

16. Shapovalov V.I. (1996) Structure and Entropy. Shapovalov // Chemistry and Life. - 1996. №1-3. - p. 17-24.

17. Sorokin DS, Danilov AM (2014) Regularities in composites from positions of system analysis // Young scientist. - 2014. - №10. - p. 206-208. 